\title{
Blocking of Stimulus Control in Children with Autism
}

\author{
Heidi Skorge Olaff ${ }^{1}$ (D) $\cdot$ Monica Vandbakk ${ }^{1} \cdot$ Per Holth $^{1}$
}

Accepted: 21 December 2020 / Published online: 8 February 2021

(C) The Author(s) 2021

\begin{abstract}
The present study aimed to investigate the blocking of stimulus control in three children with autism. We used a go/no-go procedure in a standard blocking paradigm. In Phase 1, we established one of two sounds or colored squares as a discriminative stimulus for touching a tablet screen. In Phase 2, a colored square was added to the sound or a sound was added to the colored square in a stimulus compound. The discrimination training continued as in Phase 1. We subsequently tested discriminative control by each of the single stimuli separately and by the compounds. Finally, after testing with no programmed consequences, we reestablished the original discrimination and replicated the test of stimulus control. The results support previous experiments by demonstrating that the establishment of discriminative control by a second stimulus by adding it to a previously established discriminative stimulus in a compound was blocked by the earlier discrimination training in all three participants. We discuss procedural details that may be critical to avoid the blocking of stimulus control in the applied field, particularly with respect to the acquisition of skills that involve multiple stimuli, such as joint attention, social referencing, and bidirectional naming.
\end{abstract}

Keywords Go/no-go $\cdot$ Blocking $\cdot$ Stimulus overselectivity $\cdot$ Bidirectional naming $\cdot$ Joint attention $\cdot$ Autism

The phenomenon of blocking was first demonstrated in Pavlovian, or classical, conditioning (Kamin, 1969). Blocking refers to the fact that previously conditioning of a stimulus prevents conditioning of a new stimulus, which is presented simultaneously with the first. A standard blocking procedure has two acquisition phases: for example, an animal may be repeatedly exposed to a formerly neutral stimulus, say a light, immediately followed by an unconditioned stimulus (US), say food, until the animal salivates when the light is presented alone. At this point, the light has become a conditioned stimulus (CS1). After the same number of additional conditioning trials, with the light (CS1) and a tone (CS2) presented together in a compound stimulus prior to the US, the single stimuli involved and the compounds are tested separately and together for stimulus control (CS1, CS2, CS1+CS2). Test results typically show that the animal does not show increased salivation to the tone (CS2) when the tone is presented alone on test trials. The

Heidi Skorge Olaff

heidi.olaff@oslomet.no

1 Faculty of Health Science, The Institute of Behavioural Sciences, OsloMet - Oslo Metropolitan University, Postbox 4, St. Olavs Plass, 0130 Oslo, Norway previous pairings of CS1 and the US is then said to have blocked the establishment of stimulus control by CS2. Blocking in classical conditioning has been shown in experiments with rats (e.g., Blaisdell, Gunther, \& Miller, 1999; Cheatle \& Rudy, 1978; Fowler, Goodman, \& DeVito, 1977; Mackintosh, 1975; Taylor, Joseph, Balsam, \& Bitterman, 2008), pigeons (e.g., Mackintosh \& Honig, 1970; Palmer, 1988; Williams, 1975), rabbits (e.g., Stickney \& Donahoe, 1983), and humans (Arcediano, Matute, \& Miller, 1997; Bergen, 2002; Delgado, 2016; Kimmel \& Bevill, 1991; Martin \& Levey, 1991).

Although blocking was first described in studies of classical conditioning, the effect has also been demonstrated in operant discrimination training, with rats (e.g., Seraganian \& vom Saal, 1969; vom Saal \& Jenkins, 1970), rabbits (e.g., Stickney \& Donahoe, 1983), and humans, in children (e.g., Didden, Prinsen, \& Sigafoos, 2000; Dittlinger \& Lerman, 2011; Lyczak \& Tighe, 1975; Otto, 2006; Singh \& Solman, 1990) as well as in adults (e.g., Clough, Meyer, \& Miguel, 2016; Rehfeldt, Dixon, Hayes, \& Steele, 1998).

Research on the use of extra-stimulus prompts has aimed to evaluate whether the interference of pictures on the acquisition of reading skills was an instance of blocking by previously established discriminative stimuli in the form of corresponding pictures. The overall results from these studies were that 
the acquisition of sight-word reading was faster when the word was presented as a single stimulus than when presented in a compound with a picture (e.g., Didden et al., 2000; Dittlinger \& Lerman, 2011; Otto, 2006; Singh \& Solman, 1990; Wu \& Solman, 1993). Stimulus control was achieved more clearly by the pictures that the participants could tact before the experiment started. In contrast, control by the added written words presented during the blocking condition (Condition A) was blocked. The results suggested that pictorial prompts should be applied with caution when teaching textuals (i.e., reading aloud) because they may inhibit rather than strengthen appropriate stimulus control (Didden et al., 2000; Dittlinger \& Lerman, 2011; Singh \& Solman, 1990; Wu \& Solman, 1993). Thus, the transfer of stimulus control from the pictorial stimuli to the written words was impaired. These studies demonstrated that the picture prompts functioned as a blocking element and inhibited accurate textual responses. In fact, the number of correct textuals was higher in the presence of the written words alone than in the condition where pictorial prompts were used (Solman, Singh, \& Kehoe, 1992; Wu \& Solman, 1993).

Lyczak and Tighe (1975) investigated blocking in a series of sorting tasks, (discrimination of food and vehicles) with children aged 6-9. In all experimental conditions, an initial training phase established the sorting of stimuli according to one dimension (A), which was relevant to the solution (i.e., size, color or shape). In a second training phase, a second dimension (B) was equally relevant to the solution. Finally, they tested whether control by B had been blocked by the formerly established control of sorting by dimension A. Such blocking was only observed when the transition between training phases and between training and test was made inconspicuous by progressing across phases with minimal delays and no instructions that emphasized differences from the previous phases.

Researchers have suggested that blocking is likely related to stimulus overselectivity, in which some relevant properties of a compound stimulus fail to acquire stimulus control (e.g., Cengher, Budd, Farrell, \& Fienup, 2018; Cipani, 2012; Farber, Dickson, \& Dube, 2017; Lovaas, Schreibman, Koegel, \& Rehm, 1971; Ploog, 2010). Such narrow attending may be maladaptive and is sometimes associated with children with autism (Dube et al., 2016; Lovaas et al., 1971). However, Dube et al. (2016) found no significant differences in overselective responding when comparing a group of children with autism with typically developing children, and children with Downs syndrome when these groups were matched according to developmental level.

Nevertheless, the blocking effect may have implication for teaching children with autism when a skill requires attending to multiple stimuli. For example, joint attention skills depend on simultaneous attending to multiple stimuli, such as the adult's gaze direction, pointing, and the spoken word "Look!" and an object with multiple stimulus elements (e.g., color, shape, texture or function; Ploog, 2010). Likewise, Michael, Palmer, and Sundberg (2011) argued that in verbal behavior multiple control is the rule rather than the exception, and standard listener skills involve conditional discriminations, such as matching to sample, responding to different relations, or instructions, in which a three-term contingency is brought under the control of a conditional stimulus. Examples include responding to instructions (e.g., Sundberg, 2020), matching to sample, and bidirectional naming - where the establishment of listener skills result in the emergence of corresponding verbal skills or vice versa (Horne \& Lowe, 1996). Research into the circumstances under which blocking occurs may have implications for how to arrange effective discrimination training to establish joint attention and bidirectional naming for children with autism. Moreover, such research may be useful with respect to refinement of standard procedures for establishing social conditioned reinforcers.

In a recent study, Vandbakk, Olaff, and Holth (2020) demonstrated blocking of stimulus control in rats using an operant conditioning procedure. In the first phase of a go/no-go procedure, either of two single stimuli, one auditory and one visual, was established as a positive discriminative stimulus (S+) for chain pulling, and the second as a negative discriminative stimulus (S- or S-delta). An unconditioned reinforcer (water) was produced contingent on chain pulling in the presence of the S+. In the second phase, a compound tone-light/light-tone stimulus was used the same way as the single stimulus in the previous phase. Following training, tests of stimulus control and conditioned reinforcer properties were conducted. The result showed limited stimulus control by the added stimulus, which had not been established as an S+ during the first phase. Moreover, the added stimulus did not show reinforcing properties when contingent upon a novel response. Thus, Vandbakk et al. (2020) supported previous research on the blocking effect in animals using an operant discrimination training procedure.

The authors of this article suggest that procedures that facilitate blocking of stimulus control may influence the establishment of stimulus control and conditioned reinforcers in applied settings. The present study aimed to replicate parts of Vandbakk et al. (2020) in an applied context. Thus, we investigated whether blocking could be demonstrated in children with autism during the establishment of stimulus control, using a standard operant discrimination procedure (e.g., Seraganian \& vom Saal, 1969; Vandbakk et al., 2020; vom Saal \& Jenkins, 1970).

\section{Method}

\section{Participants}

Three boys, aged 3-6 and diagnosed with autism, participated in the current study. Eric was 6 years old; Roy was 3, and Ted 
was 4 at the time of the experiment. The participants' parents gave their informed consent for participation in the study, and the Norwegian research ethical committee approved the study. All participants received early intensive behavioral intervention in their public day care center. The participants had no additional health issues. All participants had acquired some vocal verbal behavior and basic social skills, such as saying "High-five" and "Thank you" appropriately to other persons.

Before the current experiment, verbal behavior was tested using the Assessment of Basic Language and Learning SkillsRevised (ABLLS-R; see Partington, 2006). However, only skill areas most relevant to cooperation and reinforcer effectiveness, visual performance skills, and verbal behavior were included in the assessment: (a) Cooperation and Reinforcer Effectiveness; (b) Visual Performance; (c) Receptive Language; (d) Motor Imitation; (e) Vocal Imitation; (f) Requests; (g) Labeling; (h) Intraverbals; (i) Spontaneous Vocalization; and (j) Syntax and Grammar; and (p) Generalized Responding. Scores for each child are shown in the Appendix. We considered acquired verbal behavior as the most relevant area related to the present research question. Hence, additional social skills, reading, spelling, math, and basic life skills were not assessed in detail, but all three children were able to play simple games with their peers, and selfhelp skills were age-appropriate.

\section{Setting}

The study was conducted in each child's day care center. All participants had a separate training room available with a table and two chairs. This training room was used during all experimental sessions. The researcher was either positioned next to the child (Eric) or across the table (Roy and Ted). Daily sessions were run on weekdays over 5 weeks.

\section{Stimuli}

During discrimination training and stimulus control tests, visual and auditory stimuli were used. Visual stimuli were colored squares presented on the monitors, whereas the auditory stimuli were tones produced by the computer speaker. The colors of the visual stimuli and the type of auditory stimuli were randomly selected from the Microsoft Office "wav" tones and its color panel. Table 1 provides an overview of the stimuli used in both training phases.

\section{Assessment of Preferred Stimuli}

To assess potential reinforcers, we used a multiple stimulus assessment without replacement (DeLeon \& Iwata, 1996). Edibles were not used for Eric, whereas for the other two participants, raisins, grapes, and small pieces of gingerbread were delivered as immediate consequences of completing a session. Preferred video clips, as identified by the children's parents, were downloaded from YouTube. Titles of video clips are shown in Table 2. New similar video clips were identified during Phase 1 for Roy, to avoid saturation. For Ted, the video clips were saved in different folders to avoid that the same video clip was used twice in succession. Throughout the entire experiment, the duration of the preferred video clips was $8 \mathrm{~s}$ for all participants.

\section{Apparatus}

Three Acer Aspire Switch 10,1" computers with a touch screen and operating system Windows 8 were used during the entire experiment, one computer for each participant. Each computer had a detachable screen, which functioned as a tablet with an integrated speaker. Experimental conditions and data recording was controlled by software developed in Microsoft Visual Basic 1.0, 2010 Express by the third author.

A $7.0 \times 7.0 \mathrm{~cm}$ sized square in the middle of the screen was present throughout all training and test sessions and served as the main response key (as illustrated in Fig. 1). The background of the screen was light gray. All visual stimuli were presented by changing the color of the initially white square. The changed color was either an $\mathrm{S}^{+}$or an $\mathrm{S}^{-}$. The number of touches on the main key on the computer screen was automatically recorded through the Visual Basic program in separate files and imported to an Excel file by the researchers. The experimenter could pause, restart, or close the program if necessary, by pressing specific keys on the keyboard.

\section{Procedure}

All training sessions were initiated by the presentation of the computer screen and a vocal instruction by the experimenter: "I will now show you something on the screen, pay attention." Either one of six quasi-randomly mixed sequences of $\mathrm{S}^{+}$and $\mathrm{S}^{-}$presentations was selected for each session. The number of training trials per session was gradually increased from 6 to 20, whereas test sessions consisted of 24 trials. Regardless of the number of trials, the number of $\mathrm{S}^{+}$was always equal to the number of $\mathrm{S}^{-}$trials.

The participants completed four to five sessions per day during Phase 1, and six to eight sessions during Phase 2. Each session lasted approximately 1-2 min. Between sessions, the participants were given a play break. The play breaks were arranged either in the teaching room or with peers in the daycare center. Experimental sessions were scheduled throughout the day at the daycare center between 9 A.M. and 5 P.M. The sessions were carried out as a part of the participants' regular instructional sessions, which were usually completed 1-2 $\mathrm{hr}$ before lunch and 1-2 $\mathrm{hr}$ after lunch. 
Table 1 Overview of stimuli presented during Phases 1 and 2

\begin{tabular}{|c|c|c|c|c|}
\hline \multirow[t]{2}{*}{ Participants } & \multicolumn{2}{|c|}{ Phase 1: Single stimuli } & \multicolumn{2}{|l|}{ Phase 2: Compound stimuli } \\
\hline & $\mathrm{S}_{1}^{+}$ & $\mathrm{S}_{1}^{-}$ & $\mathrm{S}_{1}^{+} \mathrm{S}_{2}^{+}$ & $\mathrm{S}_{1}{ }^{-} \mathrm{S}_{2}^{-}$ \\
\hline Eric & Purple Square & Yellow Square & Purple Square + Whoosh Sound & Yellow Square + Beep Sound \\
\hline Roy & Whoosh Sound & Beep Sound & Whoosh Sound + Green Square & Beep Sound + Red Square \\
\hline Ted & Green Square & Red Square & Green Square + Whoosh Sound & Red Square + Beep Sound \\
\hline
\end{tabular}

Note. $\mathrm{S}_{1}{ }^{+}$and $\mathrm{S}_{1}{ }^{-}$were established first, and $\mathrm{S}_{2}{ }^{+}$and $\mathrm{S}_{2}{ }^{-}$were added in the second phase

Phase 1 and Phase 2: Go/No-Go Discrimination Training The discrimination training was a go/no-go procedure, which entails that the $\mathrm{S}_{1}{ }^{+}$and the $\mathrm{S}_{1}{ }^{-}$were presented alternately rather than simultaneously. The purpose of Phase 1 was to establish stimulus control over one response, touching the main key in the presence of $\mathrm{S}_{1}{ }^{+}$. The target responses were differentially reinforced in the presence of the $\mathrm{S}_{1}{ }^{+}$(i.e., "go") by the immediate onset of a preferred video clip, described in Table 2. In the presence of the visual or auditory $\mathrm{S}_{1}{ }^{-}$(i.e., "no-go"), touch responses did not produce any programmed consequences. All participants started with two 6-trial sessions; three $\mathrm{S}^{+}$and three $\mathrm{S}^{-}$trials. The number of trials gradually increased up to 20 over successive sessions. Responses to the main key within the 5.2-s duration of the $\mathrm{S}^{+}$(the discriminative stimulus) led to the onset of the preferred video clip (the reinforcer).

Phase 2 involved the same type of go/no-go training as Phase 1. However, the discrimination was between two stimulus compounds rather than between single stimuli. On successive trials, either a novel auditory $\mathrm{S}_{2}{ }^{+}$was added to the previously established visual $\mathrm{S}_{1}{ }^{+}$, and another novel auditory $\mathrm{S}_{2}{ }^{-}$was added to the previously established visual $\mathrm{S}_{1}{ }^{-}$(for Ted and Eric) or novel visual stimuli, $\mathrm{S}_{2}{ }^{+}$and $\mathrm{S}_{2}{ }^{-}$were added to the formerly established auditory $\mathrm{S}_{1}{ }^{+}$and $\mathrm{S}_{1}{ }^{-}$, respectively (for Roy; see Table 1). Responses in the presence of the $\mathrm{S}_{1}{ }^{+}$and the added stimulus $\left(\mathrm{S}_{2}{ }^{+}\right)$were followed by reinforcement. The reinforcement schedule was gradually thinned from continuous reinforcement to variable ratio (VR) 5. The number of trials in Phase 2 was yoked to the number of trials necessary to acquire stimulus control in Phase 1.
Prompting Prompts were (1) pointing to and/or physically guiding touches to the monitors; (2) physically obstructing responses in the absence of $\mathrm{S}^{+}$, including in the presence of $\mathrm{S}^{-}$; and (3) pointing to and/or physically guiding touches on the trial-initiation key. The obstruction of touches on the main key in the absence of $\mathrm{S}^{+}$in Phase 1 was accomplished by the researcher putting her hand in front of the tablet's screen whenever the child moved its hand toward it. The prompts were faded across trials. Additional prompts and praise were used with Roy only: vocal prompts used were instructions such as "Wait" and "Listen." General vocal praise from the researchers, such as nods, smiles, "Great job with the tablet." "Nice sitting on your chair," and "You are doing great," were presented intermittently. Roy received intermittent praise for working on the tablet throughout the experiment.

Limited Hold At first, the duration of both the visual and the auditory stimuli was $5.2 \mathrm{~s}$. However, the duration of the stimuli was shortened for Roy and Ted during training in Phase 1. Responding to $\mathrm{S}^{+}$within the time limit (i.e., the limited hold) interrupted the duration of the stimulus and resulted in a preferred video clip playing on the tablet screen. In contrast, responses to the main key in the presence of $\mathrm{S}^{-}$or during the Intertrial Interval (ITI) had no programmed consequences other than initiating a reset delay as described below.

Reset Delay To avoid the adventitious reinforcement of touching the square in the absence of the $\mathrm{S}^{+}$, we used a reset delay: if the participants touched the main key during the ITI or in the presence of $\mathrm{S}^{-}$, the next trial was postponed by a given number
Table 2 Video clips used during the experiment

\begin{tabular}{lll}
\hline Eric & Roy & Ted \\
\hline Sponge Bob & Trucks & "Join the dance 2014" \\
Larva & Garbage trucks & "Gummi bear" \\
Despicable Me & Children song game & "Until Dovre falls" \\
Ice Age & Children music & "What does the fox say" \\
Ed & Trains & "Gangnam style" \\
Edd and Eddy & Motorcycles & "Tarzan and Jane" \\
Monster University & Cars (Disney) & "The lazy song" \\
Ninja Turtles & Fantorangen (Norwegian) & \\
How to Train Your Dragon & & \\
\hline
\end{tabular}

Note. For Ted, the clips were music videos 
Fig. 1 An illustration of the placement of the white and the blue square on the screen

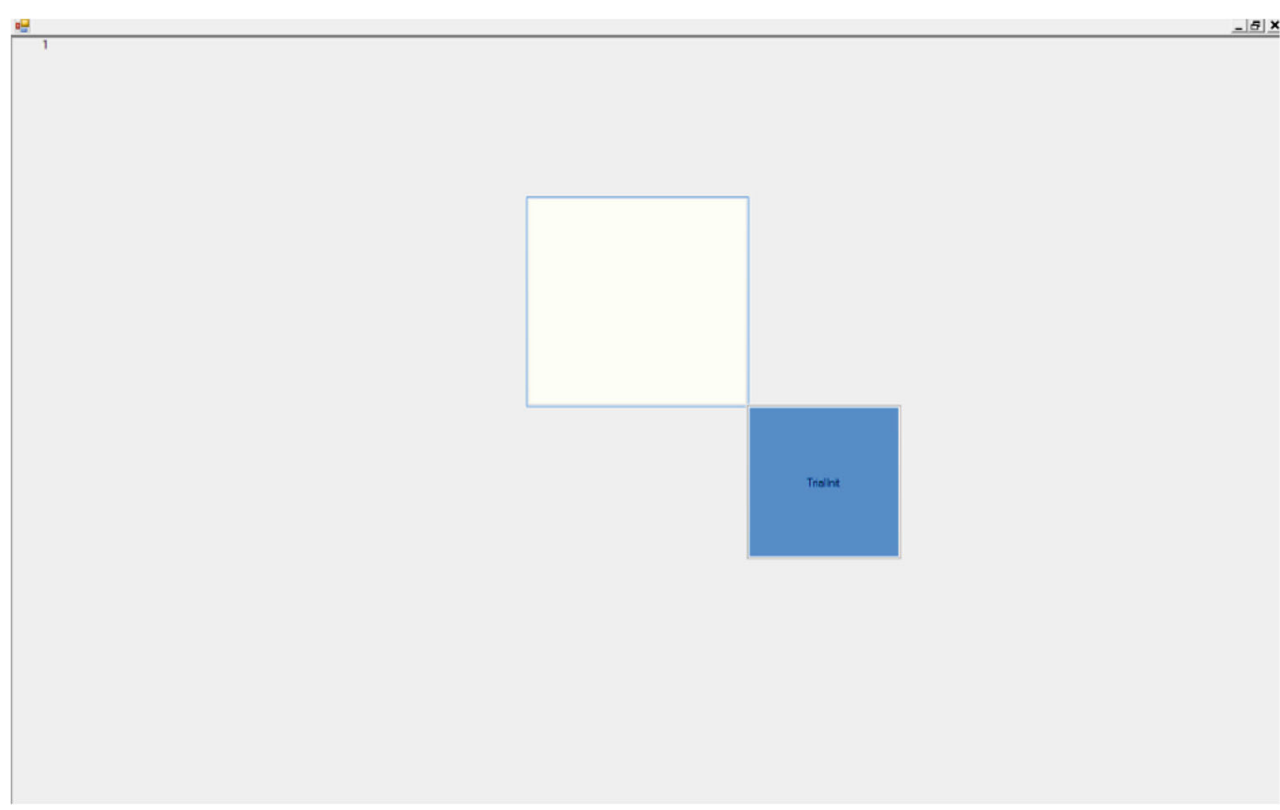

Note. A picture of the screen of the computer showing the placement of the white square and the placement of the blue square, which the participant could press to proceed to the next trial, a trial initiation response. of s. The reset delay was gradually increased from $6 \mathrm{~s}$ until stimulus control was reached according to the criteria.

Trial-Initiation Response As soon as a trial ended, a blue square $(5.0 \times 5.0 \mathrm{~cm})$ appeared on the screen (see Fig. 1), and the participant could initiate the next trial by touching it (e.g., Iversen, 1998). When the trial-initiation option was introduced, the previous automatic ITI was removed. Hence, the duration of ITI depended on how fast the participants touched the trial-initiation response button (the blue square). The trialinitiation response option was introduced from Session 13 for Eric, Session 21 for Roy, and Session 33 for Ted. The participants were trained by the experimenter prompting a response to the blue square (e.g., by pointing to it).

From Continuous to Intermittent Reinforcement Continuous reinforcement (fixed ratio 1; FR 1) was used for the establishment of stimulus control in the initial sessions. Across successive sessions in Phases 1 and 2, the schedule of reinforcement was thinned from FR1 through VR3 and VR4, to VR5, with a range of four, so that the number of responses required to produce the reinforcer varied between three and seven.

Stimulus Control Criterion The original stimulus control criterion was that responses to the main key occurred in the presence of the $\mathrm{S}^{+}$and zero responses in the presence of $\mathrm{S}^{-}$and in the absence of stimuli on $100 \%$ of the trials across two successive 20-trial sessions. However, the mastery criterion was softened for Roy to $90 \%$ mastery across two 20 -trial sessions.
Phases 3 and 5 were tests of stimulus control, whereas Phase 4 was the reestablishment of stimulus control as the final training sessions in Phase 2.

Phases 3 and 5: Tests of Stimulus Control by Simple and Compound Stimuli During a 24-trial test session, the six stimuli (i.e., each of the single stimuli $\left[\mathrm{S}_{1}{ }^{+}, \mathrm{S}_{2}{ }^{+}, \mathrm{S}_{1}^{-}\right.$, and $\left.\mathrm{S}_{2}^{-}\right]$as well as the two compounds $\left[\mathrm{S}_{1}{ }^{+} \mathrm{S}_{2}{ }^{+}\right.$and $\left.\mathrm{S}_{1}{ }^{-} \mathrm{S}_{2}{ }^{-}\right]$were presented in a quasi-randomized order: (1) the visual or auditory $\mathrm{S}^{+}$ established during Phase 1 ; (2) the visual or auditory $\mathrm{S}^{-}$ established during Phase 1; (3) the visual or auditory stimulus added to the initial $\mathrm{S}^{+}$in Phase 2; (4) the visual or auditory stimulus added to the initial $\mathrm{S}^{-}$during Phase 2; (5) compound $^{+}$ stimulus, consisting of the visual $\mathrm{S}^{+}$with an auditory stimulus added or vice versa, and (6) compound, consisting of the visual $\mathrm{S}^{-}$and an auditory stimulus added, or vice versa. Each of the stimuli was repeated four times.

During the test of stimulus control, responses to the main key produced consequences (the preferred video clips; see Table 2) to maintain responding only in the presence of the compound consisting of the original $\mathrm{S}_{1}{ }^{+}$and the added $\mathrm{S}_{2}{ }^{+}$. The video clips were contingent on responses according to a VR 5 schedule. The presentation of the compound $\mathrm{S}_{1}-\mathrm{S}_{2}{ }^{-}$was considered as a control condition, in which responses to the two stimuli presented simultaneously were never reinforced. Likewise, responses to either S presented alone were never followed by any programmed consequences.

Responses to the main key in the presence of either of the six stimulus conditions were recorded for later analysis of whether stimulus control was established. Blocking would be 
demonstrated to the extent that touch responses to the main key were more frequent in the presence of the initial $\mathrm{S}^{+}$than in the presence of the stimulus added during Phase 2 and in the presence of the $\mathrm{S}^{-}$stimuli. The primary dependent measure was the number of responses to the main key (i.e., touches on the square) in the presence of different single and compound stimuli. Stimulus control was measured by relative number of responses in the presence of the different stimulus conditions.

\section{Results}

In Phase 1, discrimination of single stimuli, the stimulus control criterion of $100 \%$ accuracy in two successive 20-trial sessions was achieved after a total of 900 training trials (Sessions 49-50) for Eric, and after 1,038 trials (Sessions 62-63) for Ted. For Roy, the stimulus control criterion of $90 \%$ mastery in two consecutive 20-trial sessions was met after a total of 850 training trials (Sessions 55-56). During the first eight sessions Roy emitted more responses in the absence of stimuli (up to 89 responses), than in the presence of both $\mathrm{S}_{1}{ }^{+}$and $\mathrm{S}_{1}{ }^{-}$. Therefore, during Sessions 9-12, we focused on training the discrimination between the $\mathrm{S}_{1}{ }^{+}$and absence of stimuli, rather than discrimination between the two training stimuli. From Session 13, discrimination training for Roy continued by including $\mathrm{S}^{-}$trials as for Eric and Ted.

Touching the trial-initiation key was prompted in the session it was introduced for Roy and Ted, whereas Eric touched the key spontaneously. When the trial-initiation response option was introduced, the number of responses to the main key (i.e., responses in the absence of $\mathrm{S}_{1}{ }^{+}$and $\mathrm{S}_{1}{ }^{-}$) immediately dropped and stayed low for the rest of the experiment for Eric (from Session 13) and Ted (from Session 33). A reduction in the number of responses to the main key was less clear for Roy.

During Phase 2, go/no-go training with compound stimuli, the mastery criterion was achieved in fewer trials than in Phase 1. Eric reached the mastery criterion after four 20-trial sessions, Roy mastered the discrimination after three 20-trial sessions, and Ted after two 20-trial sessions. However, the participants were exposed to an equal number of trials as in Phase 1. The number of responses in the presence of the $\mathrm{S}_{1}{ }^{+}$, in the presence of the $\mathrm{S}_{1}{ }^{-}$, and in the absence of stimuli (during the ITI) in Phase 1 are shown in the left part of Fig. 2, whereas the number of responses in the presence of the compounds $\left(\mathrm{S}_{1}{ }^{+} \mathrm{S}_{2}{ }^{+}\right.$and $\left.\mathrm{S}_{1}{ }^{-} \mathrm{S}_{2}{ }^{-}\right)$as well as in the absence of stimuli during Phase 2 are shown in the right part.

In Phase 3, Test 1 of stimulus control by simple and compound stimuli, all three participants consistently emitted more responses on the four $\mathrm{S}_{1}{ }^{+}$trials than on the corresponding four $\mathrm{S}_{2}{ }^{+}$trials (Fig. 3, left panel). Thus, blocking of stimulus control was demonstrated in all participants following previous discrimination training with simple stimuli in Phase 1 and with compound stimuli in Phase 2 . In the presence of the single stimuli $\mathrm{S}_{1}{ }^{-}$and $\mathrm{S}_{2}{ }^{-}$, and the compound $\mathrm{S}_{1}{ }^{-} \mathrm{S}_{2}{ }^{-}$, two of the participants made no responses at all, whereas one (Roy) emitted relatively few responses.

During Phase 4, the reestablishment of stimulus control was achieved in two 20-trial sessions. In Phase 5, Test 2 of stimulus control by simple and compound stimuli, all participants emitted fewer responses in the presence of $\mathrm{S}_{2}{ }^{+}$, which was added in Phase 2, than in the presence of $\mathrm{S}_{1}{ }^{+}$, which was introduced during Phase 1 of the discrimination training. Thus, the demonstration of blocking was replicated. Figure 3 (right panel) shows the results from the replication of the stimulus control test (Phase 5). As in the first test, the number of responses in the presence of the single stimuli $\mathrm{S}_{1}{ }^{-}$and $\mathrm{S}_{2}{ }_{2}^{-}$, and the compound $\mathrm{S}_{1}{ }^{-} \mathrm{S}_{2}{ }^{-}$, was zero or near zero for two of the participants, whereas one (Roy) emitted a few responses in the presence of $\mathrm{S}_{2}{ }^{-}$.

During each of the four reinforced compound $\mathrm{S}_{1}{ }^{+} \mathrm{S}_{2}{ }^{+}$trials in each of the two test phases, all participants emitted four to six responses, which was the maximum number because the opportunity to respond ended with the presentation of a preferred video clip. In general, the second test confirmed the results of the first test. In particular, the higher number of responses in the presence of the four $\mathrm{S}_{1}{ }^{+}$trials than on the corresponding four $\mathrm{S}_{2}{ }^{+}$trials was consistent across the tests.

\section{Discussion}

The purpose of the present study was to investigate whether blocking of stimulus control during operant discrimination could be demonstrated in children with autism. All three participants responded more frequently in the presence of the first conditioned stimulus than in the presence of the added stimulus. Thus, control by the added stimulus was blocked. Replication of the stimulus control test showed the same consistent result: The $\mathrm{S}_{1}{ }^{+}$, which was established during the first phase of the discrimination training, was still effective, whereas $\mathrm{S}_{2}{ }^{+}$, which was added during the second phase, was not.

The results of the present study are in accord with the results of previous studies that have demonstrated blocking of discriminative control in animals (e.g., Vandbakk et al., 2020; vom Saal \& Jenkins, 1970) and in humans. However, results of previous experiments with humans have varied, and so have the procedures used in those experiments. The studies with human participants have been concerned with specific tasks, such as the use of extra-stimulus prompts in reading instruction (e.g., Didden et al., 2000) or new stimuli in compounds with stimuli that have already formed equivalence classes (e.g., Rehfeldt et al., 1998), or sorting tasks (e.g., Lyczak \& Tighe, 1975). In the study reported by Lyczak and Tighe (1975), the participants demonstrated blocking only during the condition with no specific cueing of the successive phases of training and test. Blocking was observed when the three phases appeared more continuous, as in animal studies, 

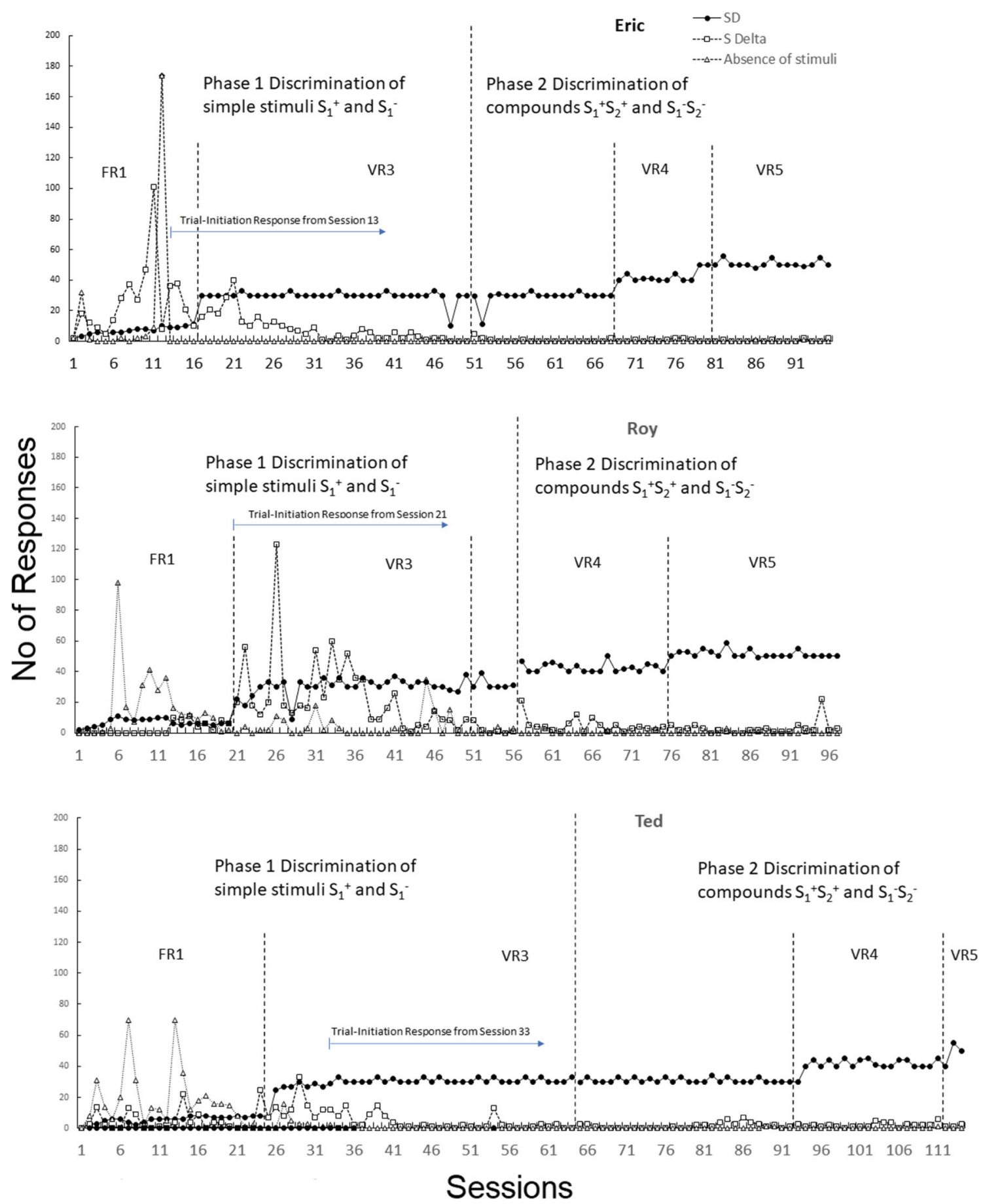

Note. The number of responses is shown on the y axis and session numbers are marked on the $\mathrm{x}$ axis. FR = Fixed Ratio and VR = Variable Ratio. The session number at which the Trial-Initiation Response Option was introduced is indicated for each participant.

Fig. 2 Successive discrimination training during Phase 1 and 2

without phases being signaled. The easily discriminable transition between the training phases could have indicated the beginnings of new training phases and, thus, explain the failure of a blocking effect of the previous training phase.
The purpose of giving phase-specific verbal instructions has been to prevent a declining response rate in the absence of continuous feedback. For example, the children have been told that "the rule of the game has changed," and that they "will receive 


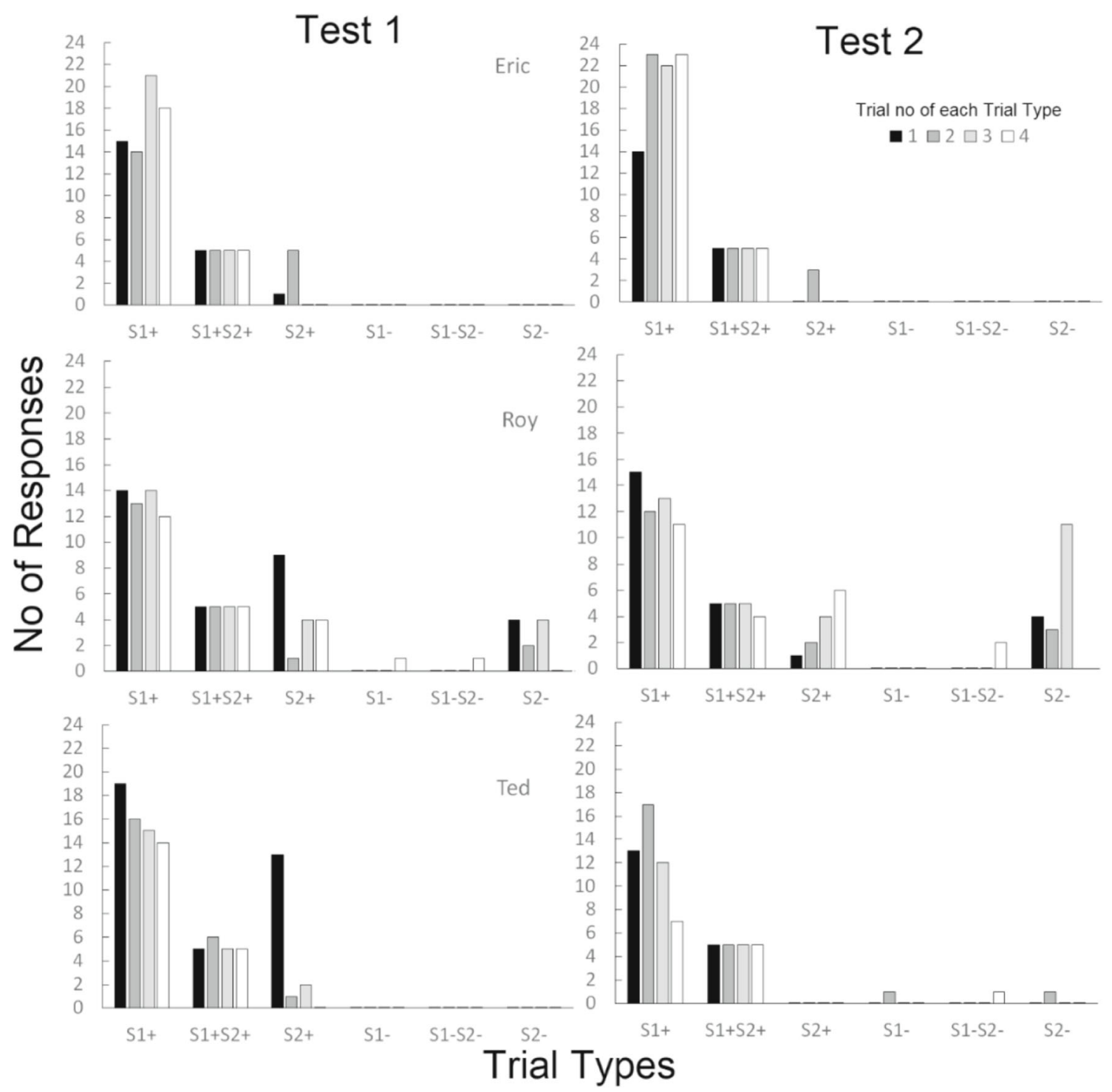

Note. The tests measured the number of responses in the presence of $\mathrm{S}_{1}^{+}$and $\mathrm{S}_{2}{ }^{+}-, \mathrm{S}_{1}{ }^{-}$and $\mathrm{S}_{2}{ }^{-}$, and in the presence of the compound $\mathrm{S}_{1}{ }^{+} \mathrm{S}_{2}{ }^{+}$and $\mathrm{S}_{1}{ }^{-} \mathrm{S}_{2}{ }^{-}$. Except in the presence of $\mathrm{S}_{1}{ }^{+} \mathrm{S}_{2}{ }^{+}$, where responses were reinforced according to a VR5 schedule, the tests were carried out in extinction. The black bars (1) represent responses during the first of each trial type, the dark grey bars (2) indicate responses during the second, light grey bars (3) represent responses during the third, and the white bars (4) indicate responses during the fourth and final trial of each type.

Fig. 3 Tests of stimulus control

the reinforcer at the end of the test session." Also, participants have been told to do as they did in the previous phase, during the discrimination training (Lyczak \& Tighe, 1975). These procedural variables probably counteracted blocking. Some other previous blocking experiments with children have avoided the problem of extinction by providing feedback, such as verbal praise, on each response during baseline and posttest (e.g., Didden et al., 2000; Singh \& Solman, 1990). An obvious problem with such continuous reinforcement during the test is that the test itself may establish discriminative control that did not derive from previous training. A strength of the present experiment is the use of an intermittent schedule of reinforcement to promote a high rate of responding during the later tests, where touching the main key was reinforced exclusively in the presence of the compound $\mathrm{S}_{1}{ }^{+} \mathrm{S}_{2}{ }^{+}$. The purpose of stretching the schedule of reinforcement during training from FR 1 to VR 5 was to prepare for response maintenance throughout the test phases while avoiding verbal instruction as well as reinforcement of the crucial test trials, $\mathrm{S}_{1}{ }^{+}$ and $\mathrm{S}_{2}{ }^{+}$. The VR 5 schedule of reinforcement implied that the participants had to touch the compound stimulus on the average five times before the responses produced the reinforcer. Therefore, during the stimulus control tests, the results show 20-21 responses in the presence of the compound $\mathrm{S}_{1}{ }^{+} \mathrm{S}_{2}{ }^{+}$for each participant. These trials were randomly interspersed 
between the other five trial types. Without this intermittent reinforcement, the participants' behavior during the stimulus control tests might have extinguished rapidly during the tests. However, despite reinforced responding to the compound stimulus, the stimulus control tests of the two stimuli separately showed an explicit control by $\mathrm{S}_{1}{ }^{+}$, but not by the later added $\mathrm{S}_{2}{ }^{+}$.

The go/no-go discrimination implies control by the negative as well as by the positive discriminative stimulus. For all participants, the establishment of the go/no-go discrimination took from 850 to 1,038 trials to reach the criterion of $90 \%-$ $100 \%$ accuracy in two successive sessions. Although responses to the main key in the presence of $\mathrm{S}_{1}{ }^{+}$occurred immediately following the startup instruction, not responding in the absence of $\mathrm{S}_{1}{ }^{+}$, including in presence of the $\mathrm{S}_{1}{ }^{-}$, took more trials to establish. A history of tablet use may explain the speed with which responding to the main key on the tablet was established, as well as slowness of refraining from responding in the absence of $\mathrm{S}_{1}{ }^{+}$. It may be presumed that once responding is established, its removal in the presence of the negative discriminative stimulus (in this case, the $\mathrm{S}_{1}{ }^{-}$) requires differential extinction or punishment in the presence of that stimulus. Three features of the procedure may have worked to eventually produce the required go/no-go discrimination: First, the reset delay prevented the adventitious reinforcement of responding to the main key in the absence of $\mathrm{S}_{1}{ }^{+}$. Second, the limited hold and the intermittency of reinforcement may both have sharpened the control by the $\mathrm{S}_{1}{ }^{+}$by hindering discriminative control by the reinforcing consequences. Third, the introduction of the trial-initiation option seemed to effectively reduce the number of responses to the main key during ITIs by providing an alternative.

Once control by the negative $S_{1}{ }^{-}$(as well as by the positive $\mathrm{S}_{1}^{+}$) is established, an intriguing question is whether the negative control by the later introduced $\mathrm{S}_{2}{ }^{-}$will be blocked (as well as the positive control by $\mathrm{S}_{2}^{+}$). Such blocking of control by the negative $\mathrm{S}_{2}{ }^{-}$was indicated in the case of one participant only: Roy responded more frequently in the presence of $\mathrm{S}_{2}{ }^{-}$ than in the presence of $\mathrm{S}_{1}{ }^{-}$during both tests. It is possible that some apparent blocking of control by the S2- in the case of Roy was predictable from the fact that he responded more frequently than the other two participants to the $\mathrm{S}^{-}$stimuli throughout most of the training. It is also possibly relevant that only Roy was first introduced to auditory stimuli (as $\mathrm{S}_{1}{ }^{+}$ and $\mathrm{S}_{1}{ }^{-}$) and then to visual stimuli (as $\mathrm{S}_{2}{ }^{+}$and $\mathrm{S}_{2}{ }^{-}$), whereas the other two participants (Eric and Ted) were first exposed to visual stimuli (as $\mathrm{S}_{1}{ }^{+}$and $\mathrm{S}_{1}{ }^{-}$) and next to auditory stimuli (as $\mathrm{S}_{2}{ }^{+}$and $\mathrm{S}_{2}{ }^{-}$). Roy, who was exposed to auditory stimuli first, also showed slightly less blocking than the participants who were exposed to visual stimuli first. However, it must be listed as a limitation of the present experiment that it included the reverse introduction of auditory and visual stimuli for one participant only. Thus, order effects of visual and auditory stimuli were thoroughly investigated neither within nor across participants. Possible order effects, along with the extent to which blocking of negative control by a new stimulus is predictable from the strength of the original $\mathrm{S}^{-}$control should be investigated in future research.

Cengher et al. (2018) found stimulus prompting more effective than response-prompting procedures and suggested that blocking or overshadowing may shed light on the difference. Often, stimulus prompts consist of highlighting a trait of a stimulus with no specific prior conditioning history, then gradually fading that trait (e.g., emphasize the color blue on a sight word and gradually fading the text until the individual says "Blue" in the presence of a blue card). In contrast, response prompts typically have a conditioning history (e.g., vocal instructions, physical guidance, or adding a picture to facilitate the reading of words) and thus have discriminative properties. Thus, response prompts may inhibit the establishment of stimulus control of a second $\mathrm{S}^{+}$. An alternative variant of the superiority of stimulusprompting procedures (or intra-stimulus prompts) over response prompt (or extra-stimulus prompts) procedures is overshadowing. Unlike blocking, overshadowing does not depend on a prior conditioning history. When two stimuli are presented together, one stimulus may acquire control stronger or more quickly than the other (e.g., a picture may be more salient than a visible word in a sight-word reading task).

Stimulus overselectivity has been widely accepted as a hindrance to the establishment of stimulus control in children with autism (e.g., Lovaas et al., 1971). On the other hand, Dube et al. (2016) found that stimulus overselectivity reflects mental age rather than the diagnosis of autism. Stimulus overselectivity, whether autism-specific or not, is still a problem that may require specific attention whenever it occurs. Hence, it is important to investigate the conditions under which stimulus overselectivity occurs and to find applied solutions to such blocking of stimulus control.

Whether problems of restricted stimulus control are called stimulus overselectivity, differences in stimulus salience, selective attention, overshadowing, or blocking, the key to solving the problem, we presume, lies in changing the contingencies. It is fortunate that stimulus overselectivity and blocking may be reduced by teaching an overt precurrent ("observing") response to the $\mathrm{S}^{+}$(Doughty \& Hopkins, 2011), as well as by teaching conditional discrimination from the beginning of a procedure, rather than following a simple discrimination (Green, 2001). Moreover, Farber et al. (2017) suggested that differential observing responses (e.g., different tacts to sample stimuli) during matching-to-sample resulted in less overselectivity than nondifferential observing responses, where the response to the sample is the same on every trial, in children with autism (e.g., Reed, Altweck, Broomfield, Simpson, \& McHugh, 2012). Differential observing responses verify the discrimination of stimulus features that differ among the samples (e.g., by tacting the sample stimuli). Therefore, in cases where blocking has been demonstrated, 
the effect of establishing differential observing responses to each sample should be investigated.

Blocking of conditioned reinforcers is shown in pigeons (e.g., Palmer, 1988) and rats (e.g., Vandbakk et al., 2020), and is strongly indicated in children with autism (e.g., Lovaas et al., 1966). In applied contexts, it is likely that the conditioning of a new stimulus as a reinforcer will sometimes fail: for example, if a smile already functions as a reinforcer, establishing "Great!" as a reinforcer might be hampered or blocked if it appears in a compound with the smile. Such blocking of conditioned reinforcers may become a significant problem for children with autism, because without a range of effective social conditioned reinforcers, social skills and other complex skills are not likely to develop (e.g., Du, Broto, \& Greer, 2015; Eby \& Greer, 2017; Ferster, 1961; Greer \& Du, 2015; Lepper \& Petursdottir, 2017; Lugo, Mathews, King, Lamphere, \& Damme, 2017; Schmelzkopf, Greer, SingerDudek, \& Du, 2017). Therefore, the identification of obstacles for the successful establishment of commonly effective social reinforcers may be fundamental to the learning of important skills by children with autism (Dozier, Iwata, ThomasonSassi, Worsdell, \& Wilson, 2012; Eby \& Greer, 2017; Lovaas et al., 1966; Rodriguez \& Gutierrez, 2017), including tacts (Eby \& Greer, 2017), joint attention (Isaksen \& Holth, 2009; Jones \& Carr, 2004) and complex verbal behavior, such as bidirectional naming (Olaff \& Holth, 2020). In future research with children with autism, a possible blocking of standard social consequences as conditioned reinforcers should be investigated. Paving the way for effective conditioning of social reinforcers might prepare for the natural environments to automatically shape relevant verbal and social skills, including bidirectional naming and joint attention, and thus reduce the need for contrived intensive skill training (Holth, 2012).
The present experiment demonstrated blocking during the tests of stimulus control. To the best of our knowledge, the current study is the first that explicitly used an operant blocking paradigm with participants with autism. However, replications are needed to investigate the scope and the limits of blocking by earlier discrimination training. Problems with the establishment of novel stimuli as conditioned reinforcers as well as problems of stimulus overselectivity in children with autism may boil down to blocking and overshadowing. Future research on blocking and overshadowing as well as effective interventions to overcome these problems may benefit people with autism.

Acknowledgements We want to thank Cecilie Belinda Jørgensen, Ragnhild Kjellesvig, and Helene Bystrøm for their assistance with the data collection and their inspiring comments.

Funding Open Access funding provided by OsloMet - Oslo Metropolitan University. The experiment was funded by Oslo Metropolitan University, Faculty of Health, Institute for Behavioral Sciences.

Data Availability The data generated during the present experiment are available from the first and the third author on request.

\section{Compliance with Ethical Standards}

Ethical Approval In advance, the Norwegian Center for Research Data approved the present experiment.

Informed Consent to Participate and for Publication Informed consent was obtained from all participants' caregivers, as well as from the managers of the kindergartens the participants attended.

Conflict of Interest The authors declare that there is no conflict of interest.

\section{Appendix}

Table 3 Summary of the description of the participants according to age, diagnosis, standard Vineland scores and ABLLS-R scores, and verbal description

\begin{tabular}{|c|c|c|c|}
\hline Participants & Age & Diagnosis & ABBLS-R scores - $\%$ mastery of verbal behavior domains \\
\hline Eric & $6: 0$ & Childhood autism & $\begin{array}{l}\text { Cooperation and reinforcement effectiveness: } 91.1 \% \\
\text { Visual Performance: } 100 \% \\
\text { Receptive Language: } 98.9 \% \\
\text { Motor Imitation: } 100 \% \\
\text { Vocal Imitation: } 98.2 \% \\
\text { Requests: } 100 \% \\
\text { Labeling: } 95.7 \% \\
\text { Intraverbals: } 96.1 \% \\
\text { Spontaneous vocalizations: } 100 \% \\
\text { Syntax and Grammar: }-90.4 \% \\
\text { Generalized Responding: }-100 \%\end{array}$ \\
\hline
\end{tabular}


Table 3 (continued)

\begin{tabular}{|c|c|c|c|}
\hline Participants & Age & Diagnosis & ABBLS-R scores - $\%$ mastery of verbal behavior domains \\
\hline Roy & $3: 0$ & Childhood autism & $\begin{array}{l}\text { Cooperation and reinforcement effectiveness: } 66 \% \\
\text { Visual Performance: } 30 \% \\
\text { Receptive Language: } 48 \% \\
\text { Motor Imitation: } 27 \% \\
\text { Vocal Imitation: } 54 \% \\
\text { Requests: } 31 \% \\
\text { Labeling: } 22 \% \\
\text { Intraverbals: } 15 \% \\
\text { Spontaneous vocalizations: } 75 \% \\
\text { Syntax and Grammar: } 36 \% \\
\text { Generalized Responding: } 58 \%\end{array}$ \\
\hline Ted & 4:0 & Childhood autism & $\begin{array}{l}\text { Cooperation and reinforcement effectiveness: } 85 \% \\
\text { Visual Performance: } 55 \% \\
\text { Receptive Language: } 25 \% \\
\text { Motor Imitation: } 24 \% \\
\text { Vocal Imitation: } 20 \% \\
\text { Requests: } 7 \% \\
\text { Labeling: } 1 \% \\
\text { Intraverbals: } 0 \% \\
\text { Spontaneous vocalizations: } 14 \% \\
\text { Syntax and Grammar: } 0 \% \\
\text { Generalized Responding: } 17 \%\end{array}$ \\
\hline
\end{tabular}

Note. ABLLS-R is an acronym for Assessment of Basic Language and Learning Skills, Revised and is summarized as percent achievement per skill domains at intake in the study

Open Access This article is licensed under a Creative Commons Attribution 4.0 International License, which permits use, sharing, adaptation, distribution and reproduction in any medium or format, as long as you give appropriate credit to the original author(s) and the source, provide a link to the Creative Commons licence, and indicate if changes were made. The images or other third party material in this article are included in the article's Creative Commons licence, unless indicated otherwise in a credit line to the material. If material is not included in the article's Creative Commons licence and your intended use is not permitted by statutory regulation or exceeds the permitted use, you will need to obtain permission directly from the copyright holder. To view a copy of this licence, visit http://creativecommons.org/licenses/by/4.0/.

\section{References}

Arcediano, F., Matute, H., \& Miller, R. R. (1997). Blocking of Pavlovian conditioning in humans. Learning \& Motivation, 28, 188-199, Article LM960957. https://doi.org/10.1006/lmot.1996.0957.

Bergen, A. E. (2002). Blocking of stimulus control over human operant behavior (Master's thesis). ProQuest Dissertations \& Theses Global. Ann Arbor. Retrieved from http://hdl.handle.net/1993/19578. Accessed 27 Aug 2015.

Blaisdell, A. P., Gunther, L. M., \& Miller, R. R. (1999). Recovery from blocking achieved by extinguishing the blocking CS. Animal Learning \& Behavior, 27(1), 63-76. https://doi.org/10.3758/ BF03199432.
Cengher, M., Budd, A., Farrell, N., \& Fienup, D. M. (2018). A review of prompt-fading procedures: Implications for effective and efficient skill cquisition. Journal of Developmental \& Physical Disabilities, 30(2), 155-173. https://doi.org/10.1007/s10882-017-9575-8.

Cheatle, M. D., \& Rudy, J. W. (1978). Analysis of second-order odoraversion conditioning in neonatal rats: Implications for Kamin's blocking effect. Journal of Experimental Psychology: Animal Behavior Processes, 4(3), 237-249. https://doi.org/10.1037/00977403.4.3.237.

Cipani, E. (2012). Stimulus overselectivity: Empirical basis and diagnostic methods. Behavior Analyst Today, 13(1), 3-11. https://doi.org/ 10.1037/h0100712.

Clough, C. W., Meyer, C. S., \& Miguel, C. F. (2016). The effects of blocking and joint control training on sequencing visual stimuli. Analysis of Verbal Behavior, 32(2), 242-264. https://doi.org/10. 1007/s40616-016-0067-1.

DeLeon, I. G., \& Iwata, B. A. (1996). Evaluation of a multiple-stimulus presentation format for assessing reinforcer preferences. Journal of Applied Behavior Analysis, 29(4), 519-533. https://doi.org/10.1901/ jaba.1996.29-519.

Delgado, D. (2016). Blocking in humans: Logical reasoning versus contingency learning. The Psychological Record, 66(1), 31-40. https:// doi.org/10.1007/s40732-015-0148-x.

Didden, R., Prinsen, H., \& Sigafoos, J. (2000). The blocking effect of pictorial prompts on sight-word reading. Journal of Applied Behavior Analysis, 33(3), 317-320. https://doi.org/10.1901/jaba. 2000.33-317.

Dittlinger, L. H., \& Lerman, D. C. (2011). Further analysis of picture interference when teaching word recognition to children with 
autism. Journal of Applied Behavior Analysis, 44(2), 341-349. https://doi.org/10.1901/jaba.2011.44-341.

Doughty, A. H., \& Hopkins, M. N. (2011). Reducing stimulus overselectivity through an increased observing-response requirement. Journal of Applied Behavior Analysis, 44(3), 653-657. https://doi.org/10.1901/jaba.2011.44-653.

Dozier, C. L., Iwata, B. A., Thomason-Sassi, J., Worsdell, A. S., \& Wilson, D. M. (2012). A comparison of two pairing procedures to establish praise as a reinforcer. Journal of Applied Behavior Analysis, 45(4), 721-735. https://doi.org/10.1901/jaba.2012.45-721.

Du, L., Broto, J., \& Greer, R. D. (2015). The effects of establishment of conditioned reinforcement for observing responses for 3D stimuli on generalized visual match-to-sample in children with autism spectrum disorders. European Journal of Behavior Analysis, 16(1), 82-98. https://doi.org/10.1080/15021149.2015.1065655.

Dube, W. V., Farber, R. S., Mueller, M. R., Grant, E., Lorin, L., \& Deutsch, C. K. (2016). Stimulus overselectivity in autism, down syndrome, and typical development. American Journal of Intellectual Developmental Disabilities, 121(3), 219-235. https:// doi.org/10.1352/1944-7558-121.3.219.

Eby, C. M., \& Greer, R. D. (2017). Effects of social reinforcement on the emission of tacts by preschoolers. Behavioral Development Bulletin, 22(1), 23-43. https://doi.org/10.1037/bdb0000043.

Farber, R. S., Dickson, C. A., \& Dube, W. V. (2017). Reducing overselective stimulus control with differential observing responses. Journal of Applied Behavior Analysis, 50(1), 87-105. https://doi. org/10.1002/jaba.363.

Ferster, C. B. (1961). Positive reinforcement and behavioural deficits in autistic children. Child Development, 32, 437-456. https://doi.org/ 10.1111/j.1467-8624.1961.tb05042.x.

Fowler, H., Goodman, J. H., \& DeVito, P. L. (1977). Acrossreinforcement blocking effects in a mediational test of the CS's general signaling property. Learning and Motivation, 8(4), 507519. https://doi.org/10.1016/0023-9690(77)90048-0.

Green, G. (2001). Behavior analytic instruction for children with autism: Advances in stimulus control technology. Focus on Autism \& Other Developmental Disabilities, 16, 72-85. https://doi.org/10.1177/ 108835760101600203

Greer, R. D., \& Du, L. (2015). Identification and establishment of reinforcers that make the development of complex social language possible. International Journal of Behavior Analysis \& Autism Spectrum Disorders, 1(1), 13-34.

Holth, P. (2012). Felles oppmerksomhet og kilder til ny atferd [Joint attention and the sources of novel behavior]. Norsk Tidsskrift for Atferdsanalyse [Norwegian Journal for Behavior Analysis], 39, 143-153.

Horne, P. J., \& Lowe, C. F. (1996). On the origins of naming and other symbolic behavior. Journal of the Experimental Analysis of Behavior, 65(1), 185-241. https://doi.org/10.1901/jeab.1996.65185 .

Isaksen, J., \& Holth, P. (2009). An operant approach to teaching joint attention skills to children with autism. Behavioral Interventions, 24, 215-236. https://doi.org/10.1002/bin.292.

Iversen, I. (1998). Simple and conditional visual discrimination with wheel running as reinforcement in rats. Journal of the Experimental Analysis of Behavior, 70(2), 103-121. https://doi. org/10.1901/jeab.1998.70-103.

Jones, E. A., \& Carr, E. G. (2004). Joint attention in children with autism: Theory and intervention. Focus on Autism \& Other Developmental Disabilities, 19(1), 13-26. https://doi.org/10.1901/jaba.2008.41377.

Kamin, L. J. (1969). Predictability, surprise, attention and conditioning. In B. A. Campbell \& R. M. Church (Eds.), Punishment and aversive behavior (pp. 279-296). New York, NY: Appleton-Century-Crofts.

Kimmel, H., \& Bevill, M. (1991). Blocking and unconditioned response diminution in human classical autonomic conditioning. Integrative
Physiological \& Behavioral Science, 26(2), 132-138. https://doi. org/10.1007/BF02691036.

Lepper, T. L., \& Petursdottir, A. I. (2017). Effects of response-contingent stimulus pairing on vocalizations of nonverbal children with autism. Journal of Applied Behavior Analysis. https://doi.org/10.1002/jaba. 415

Lovaas, O. I., Freitag, G., Kinder, M. I., Rubenstein, B. D., Schaeffer, B., \& Simmons, J. Q. (1966). Establishment of social reinforcers in two schizophrenic children on the basis of food. Journal of Experimental Child Psychology, 4(2), 109-125. https://doi.org/10.1016/00220965(66)90011-7.

Lovaas, O. I., Schreibman, L., Koegel, R., \& Rehm, R. (1971). Selective responding by autistic children to multiple sensory input. Journal of Abnormal Psychology, 77(3), 211-222. https://doi.org/10.1037/ $\mathrm{h} 0031015$.

Lugo, A. M., Mathews, T. L., King, M. L., Lamphere, J. C., \& Damme, A. M. (2017). Operant discrimination training to establish praise as a reinforcer. Behavioral Interventions, 32(4), 341-356. https://doi. org/10.1002/bin.1485.

Lyczak, R., \& Tighe, R. (1975). Stimulus control in children under a blocking paradigm. Child Development, 46(1), 115-122. https:// doi.org/10.2307/1128839.

Mackintosh, N. J. (1975). Blocking of conditioned suppression: Role of the first compound trial. Journal of Experimental Psychology: Animal Behavior Processes, 1(4), 335-345. https://doi.org/10. 1037/0097-7403.1.4.335.

Mackintosh, N. J., \& Honig, W. K. (1970). Blocking and enhancement of stimulus control in pigeons. Journal of Comparative \& Physiological Psychology, 73(1), 78-85. https://doi.org/10.1037/ h0030021.

Martin, I., \& Levey, A. B. (1991). Blocking observed in human eyelid conditioning. Quarterly Journal of Experimental Psychology Section B, 43(3), 233-256. https://doi.org/10.1080/ 14640749108401269 .

Michael, J., Palmer, D. C., \& Sundberg, M. L. (2011). The multiple control of verbal behavior. Analysis of Verbal Behavior, 27, 3-22. https://doi.org/10.1007/bf03393089.

Olaff, H. S., \& Holth, P. (2020). The emergence of bidirectional naming through sequential operant instruction following the establishment of conditioned social reinforcers. Analysis of Verbal Behavior, 36, 21-48. https://doi.org/10.1007/s40616-019-00122-0.

Otto, T. (2006). Experimental analysis of the blocking effect on sight word acquisition in children of kindergarten age (Doctoral dissertation, University of Manitoba). Retrieved from http://hdl.handle. net/1993/20840.

Palmer, D. C. (1988). The blocking of conditioned reinforcement (Unpublished doctoral dissertation), University of Massachusetts, Amherst, MA.

Partington, J. (2006). Assessment of basic language and learning skillsRevised (ABLLS-R): An assessment, curriculum guide and skills tracking system for children with autism or other developmental disabilities. Walnut Creek, CA: Behavior Analysis.

Ploog, B. O. (2010). Stimulus overselectivity four decades later: A review of the literature and its implications for current research in autism spectrum disorder. Journal of Autism \& Developmental Disorders, 40(11), 1332-1349. https://doi.org/10.1007/s10803-010-0990-2.

Reed, P., Altweck, L., Broomfield, L., Simpson, A., \& McHugh, L. (2012). Effect of observing-response procedures on overselectivity in individuals with autism spectrum disorders. Focus on Autism \& Other Developmental Disabilities, 27(4), 237-246. https://doi.org/ $10.1177 / 1088357612457986$.

Rehfeldt, R. A., Dixon, M. R., Hayes, L. J., \& Steele, A. (1998). Stimulus equivalence and the blocking effect. The Psychological Record, 48(4), 647-664. https://doi.org/10.1007/BF03395295.

Rodriguez, P. P., \& Gutierrez, A. (2017). A comparison of two procedures to condition social stimuli to function as reinforcers for 
children with autism. Behavioral Development Bulletin, 22(1), 159172. https://doi.org/10.1037/bdb0000059.

Schmelzkopf, J., Greer, R. D., Singer-Dudek, J., \& Du, L. (2017). Experiences that establish preschoolers' interest in speaking and listening to others. Behavioral Development Bulletin, 22(1), 44 66. https://doi.org/10.1037/bdb0000026.

Seraganian, P., \& vom Saal, W. (1969). Blocking the development of stimulus control when stimuli indicate periods of nonreinforcement. Journal of the Experimental Analysis of Behavior, 12(5), 767-772. https://doi.org/10.1901/jeab.1969.12-767.

Singh, N. N., \& Solman, R. T. (1990). A stimulus control analysis of the picture-word problem in children who are mentally retarded: The blocking effect. Journal of Applied Behavior Analysis, 23(4), 525532. https://doi.org/10.1901/jaba.1990.23-525.

Solman, R. T., Singh, N. N., \& Kehoe, E. J. (1992). Pictures block the learning of sightwords. Educational Psychology, 12(2), 143-153. https://doi.org/10.1080/0144341920120205.

Stickney, K. J., \& Donahoe, J. W. (1983). Attenuation of blocking by a change in US locus. Animal Learning \& Behavior, 11(1), 60-66. https://doi.org/10.3758/bf03212308.

Sundberg, M. (2020). Verbal behavior. In J. O. Cooper, T. E. Heron, \& W. L. Heward (Eds.), Applied behavior analysis (pp. 456-489). Harlow, UK: Pearson Education.
Taylor, K. M., Joseph, V. T., Balsam, P. D., \& Bitterman, M. E. (2008). Target-absent controls in blocking experiments with rats. Learning \& Behavior, 36(2), 145-148. https://doi.org/10.3758/LB.36.2.145.

Vandbakk, M., Olaff, H. S., \& Holth, P. (2020). Blocking of stimulus control and conditioned reinforcement. Psychological Record, 70, 279-292. https://doi.org/10.1007/s40732-020-00393-3.

vom Saal, W., \& Jenkins, H. M. (1970). Blocking the development of stimulus control. Learning \& Motivation, 1, 52-64. https://doi.org/ 10.1016/0023-9690(70)90128-1.

Williams, B. A. (1975). The blocking of reinforcement control. Journal of the Experimental Analysis of Behavior, 24(2), 215-225. https://doi. org/10.1901/jeab.1975.24-215.

Wu, H.-M., \& Solman, R. T. (1993). Effective use of pictures as extra stimulus prompts. British Journal of Educational Psychology, 63(1), 144-160. https://doi.org/10.1111/j.2044-8279.1993. tb01047.x.

Publisher's Note Springer Nature remains neutral with regard to jurisdictional claims in published maps and institutional affiliations. 